\title{
ATRIBUTOS FÍSICOS, QUÍMICOS E EROSÃO ENTRESSULCOS SOB CHUVA SIMULADA, EM SISTEMAS DE PLANTIO DIRETO E CONVENCIONAL ${ }^{1}$
}

\author{
CRISTIANE G. DA SILVA ${ }^{2}$, TEODORICO ALVES SOBRINHO ${ }^{3}$, \\ ANTONIO C. T. VITORINO ${ }^{3}$, DANIEL F. DE CARVALHO ${ }^{4}$
}

\begin{abstract}
RESUMO: Este trabalho teve como objetivo estimar as perdas de solo e água, nos sistemas de plantio direto e convencional, e foi realizado no câmpus experimental da UFMS, em Dourados - MS, em solo classificado como Latossolo Vermelho distroférrico, no período compreendido entre outubro de $2001 \mathrm{e}$ novembro de 2002. As estimativas das perdas de solo e de água foram feitas utilizando-se do infiltrômetro de aspersão InfiAsper/UFMS, regulado para aplicar chuva com intensidade de $60 \mathrm{~mm} \mathrm{~h}^{-1}$, correspondendo à energia cinética de aproximadamente $820 \mathrm{Jm}^{-2}$. Foram utilizados os seguintes tratamentos: sucessão milho-pousio; sucessão milho-trigo; sucessão milho-nabo; sucessão milhoervilhaca; sucessão milho-aveia, os quais foram avaliados nos sistemas de preparo convencional (PC) e plantio direto (PD). Com os resultados obtidos, foram ajustadas equações de regressão, com as quais foi possível obter valores de perda de solo que variaram de $5,34 \mathrm{~g} \mathrm{~m}^{-2}$ na sucessão milho-aveia a $47,75 \mathrm{~g} \mathrm{~m}^{-2}$ na sucessão milho-nabo para o PC, e de $1,09 \mathrm{~g} \mathrm{~m}^{-2}$ na sucessão milho-trigo a $4,19 \mathrm{~g} \mathrm{~m}^{-2}$ na sucessão milho-ervilhaca para o PD. As perdas de água variaram de $0,00329 \mathrm{~m}^{3} \mathrm{~m}^{-2}$ na sucessão milhoaveia a $0,00988 \mathrm{~m}^{3} \mathrm{~m}^{-2}$ na sucessão milho-nabo, e de 0,00123 a $0,00663 \mathrm{~m}^{3} \mathrm{~m}^{-2}$ na sucessão milhopousio para o $\mathrm{PC}$ e para o $\mathrm{PD}$, respectivamente.
\end{abstract}

PALAVRAS-CHAVE: simulador de chuva, sucessão de culturas, perda de solo.

\section{PHYSICS AND CHEMICAL ATTRIBUTES AND ENTER-RILL EROSION UNDER SIMULATED RAIN IN NO TILLAGE AND CONVENTIONAL SYSTEMS}

\begin{abstract}
This work was developed in order to estimate the soil and water loss in no tillage and conventional systems. The work was carried out at Experimental Center of the Federal University of Mato Grosso do Sul - UFMS, in Dourados - MS - Brazil, in a soil classified as "Latossolo Vermelho distroférrico", in a period between October, 2001, and November, 2002. Soil and water loss estimations were done using a sprinkling infiltrometer InfiAsper/UFMS, adjusted to apply a rainfall of $60 \mathrm{~mm} \mathrm{~h}^{-1}$ of intensity, corresponding to kinetic energy of $820 \mathrm{Jm}^{-2}$. The estimates were calculated in five treatments: corn-rest succession, corn-wheat succession, corn-Raphanus sativus succession, cornvetch succession, corn-oats succession, for conventional tillage system (PC) and no tillage system (PD). With the results obtained, equations of regression were adjusted. Through these equations soil loss values were observed. They varied from $5.34 \mathrm{~g} \mathrm{~m}^{-2}$ in corn-oats succession to $47.75 \mathrm{~g} \mathrm{~m}^{-2}$ in Raphanus sativus-corn succession for PC, and $1.09 \mathrm{~g} \mathrm{~m}^{-2}$ in corn-wheat succession to $4.19 \mathrm{~g} \mathrm{~m}^{-2}$ in corn-vetch succession for PD. Water loss varied from $0.00329 \mathrm{~m}^{3} \mathrm{~m}^{-2}$ in corn-oats succession to $0.00988 \mathrm{~m}^{3} \mathrm{~m}^{-2}$ in corn-Rhaphanus sativus succession and from 0.00123 to $0.00663 \mathrm{~m}^{3} \mathrm{~m}^{-2}$ in corn-rest succession for $\mathrm{PC}$ and $\mathrm{PD}$, respectively.
\end{abstract}

KEYWORDS: rainfall simulator, crop succession, soil loss.

\footnotetext{
${ }^{1}$ Extraído da dissertação de Mestrado da primeira autora.

${ }^{2}$ Mestre em Agronomia, Universidade Federal de Mato Grosso do Sul - UFMS, Dourados - MS.

${ }^{3}$ Professor Doutor, UFMS, Caixa Postal 533, Fone: (0XX67) 411.3826, Dourados - MS, talves@ nin.ufms.br

${ }^{4}$ Professor Doutor, UFRRJ, Seropédica - RJ, carvalho@ufrrj.br. Bolsista do CNPq.

Recebido pelo Conselho Editorial em: 21-11-2003

Aprovado pelo Conselho Editorial em: 12-4-2005
}

Eng. Agríc., Jaboticabal, v.25, n.1, p.144-153, jan./abr. 2005 


\section{INTRODUÇÃO}

A degradação dos solos pode ser considerada um dos mais importantes problemas ambientais. Dentre os tipos de degradação, a erosão hídrica é considerada a que mais tem afetado a capacidade produtiva dos solos, facilitada e acelerada pelo homem com suas práticas inadequadas de manejo agrícola (CARVALHO, et al., 2002). BERTONI \& LOMBARDI NETO (1985) comentam que os diferentes sistemas de cultivo propiciam diferentes condições finais de exposição do solo aos agentes erosivos, visto que promovem mobilização e cobertura vegetal diferenciada, ocasionando diferentes graus de proteção contra as perdas de água e solo. Assim, o manejo do solo tem grande influência no processo erosivo.

A retirada da vegetação e a exposição do solo à ação direta das chuvas ou irrigação causam perdas de solo e de água além de alterações em alguns de seus atributos físicos e químicos. De acordo com LOMBARDI NETO \& BERTONI (1975), a cobertura vegetal, principalmente as restevas culturais, absorve a energia cinética da chuva, não restando energia residual para provocar a desagregação do solo.

A resistência dos solos à erosão hídrica apresenta grande amplitude devido à variabilidade climática que influi na erosividade das chuvas e à variedade de solos com características diferenciadas que, conseqüentemente, refletem na erodibilidade, tornando arriscado estimar seu valor com base unicamente na classificação do solo (EL-SWAIFY \& DANGLER, 1982).

Analisando um Latossolo Vermelho-Escuro em condições de chuvas natural, em Planaltina - DF, DEDECEK et al. (1986) concluíram que a vegetação permanente, seguida da soja em semeadura direta, foi o sistema de manejo mais eficaz na redução das perdas do solo, traduzindo-se em menores valores de razão de perda de solo, em todos os estágios das culturas.

HERNANI et al. (1997) desenvolveram estudos visando a quantificar as perdas de solo por erosão e produtividade de soja e trigo sob diferentes sistemas de preparo em Latossolo Roxo, em Dourados - MS. Nesse estudo, os autores concluíram que o plantio direto foi o sistema mais eficiente no controle de perdas de solo, água e produtividade de grãos de soja e trigo. As perdas médias de solo e água por erosão, relativas aos sistemas de plantio direto, escarificação e gradagem niveladora, gradagem pesada e gradagem niveladora e aração com arado de discos e duas gradagens niveladoras, sem cobertura vegetal, foram, respectivamente, 0,$8 ; 2,8 ; 5,3 ; 7,3 \mathrm{t} \mathrm{ha}^{-1} \mathrm{ano}^{-1}$ e o fator de erodibilidade do Latossolo Roxo foi $0,0045 \mathrm{t} \mathrm{h} \mathrm{MJ}^{-1} \mathrm{~mm}^{-1}$. No entanto, esses trabalhos foram feitos com parcelas fixas e com chuva natural, o que dificulta a condução do trabalho em outras condições de solo e de manejo.

Segundo BERTOL et al. (2001), práticas diferenciadas de manejo do solo e de cultivos provocam alterações nas propriedades físicas do solo que podem manifestar-se de várias maneiras, influenciando o desenvolvimento das plantas. Assim, o solo cultivado tende, com o tempo, a ter sua estrutura original alterada pelo fracionamento dos agregados em unidades menores, com conseqüente redução no volume de macroporos e aumentos no volume de microporos e na densidade do solo. Em decorrência disso, observa-se diminuição da taxa de infiltração de água no solo, com conseqüente aumento das taxas de escoamento superficial e de erosão hídrica.

BERTOL et al. (2001), avaliando as modificações em algumas propriedades físicas de um Cambissolo Húmico alumínico, em sistemas de preparo convencional e semeadura direta, concluíram que o tipo de manejo não afetou o diâmetro médio ponderado de agregados na camada de 0-2,5 cm; nas demais camadas, no entanto, a semeadura direta apresentou valores maiores do que o preparo convencional e que a taxa de infiltração de água no solo, tanto inicial quanto final, foi maior no preparo convencional do que nos demais tratamentos. 
Tendo em vista a importância do estudo da erosão hídrica em diferentes condições edafoclimáticas e pelo fato de a microrregião de Dourados - MS, caracterizar-se como importante região produtora de grãos e de carne, desenvolveu-se este trabalho com o objetivo de estimar as perdas de solo e de água, sob chuva simulada, nos sistemas de plantio direto e convencional.

\section{MATERIAL E MÉTODOS}

\section{Aspectos Gerais}

O experimento foi realizado no Núcleo Experimental de Ciências Agrárias da Universidade

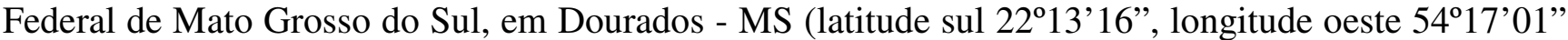
e altitude de $430 \mathrm{~m}$ ), em solo classificado como Latossolo Vermelho distroférrico, com $67 \mathrm{~g} \mathrm{~kg}^{-1} \mathrm{de}$ argila, $8 \mathrm{~g} \mathrm{~kg}^{-1}$ de silte, $9 \mathrm{~g} \mathrm{~kg}^{-1}$ de areia grossa e $16 \mathrm{~g} \mathrm{~kg}^{-1}$ de areia fina, no período compreendido entre outubro de 2001 e novembro de 2002. O clima regional classificado pelo sistema internacional de Köeppen é do tipo Cwa, clima úmido e inverno seco, com precipitação média anual de $1.500 \mathrm{~mm}$ e temperatura média anual de $22{ }^{\circ} \mathrm{C}$. As estimativas das perdas de solo e de água, sob diferentes sistemas de sucessão de culturas, foram feitas sob chuva simulada utilizando-se do infiltrômetro de aspersão InfiAsper/UFMS, desenvolvido por ALVES SOBRINHO (1997).

O infiltrômetro foi calibrado para aplicar a intensidade de precipitação de $60 \mathrm{~mm} \mathrm{~h}^{-1}$, ajustando a abertura e o número de fendas no obturador e a pressão de serviço. Para a calibração do infiltrômetro, foi utilizada uma bandeja de 1,0 $\mathrm{m}$ de comprimento por 0,7 $\mathrm{m}$ de largura colocada dentro da área de ação do equipamento. A intensidade de precipitação (Ip), em $\mathrm{mm} \mathrm{h}^{-1}$, foi estimada pela relação:

$$
\mathrm{Ip}=\frac{\mathrm{V}}{\mathrm{A} \mathrm{t}}
$$

em que,

V - volume coletado, L;

A - área de coleta, correspondente à área da bandeja, $0,70 \mathrm{~m}^{2}$, e

$\mathrm{t}$ - duração da precipitação, h.

A área de ação do infiltrômetro, ou área útil da parcela experimental $\left(0,70 \mathrm{~m}^{2}\right)$, foi contornada por um dispositivo de formato retangular construído de chapas de aço galvanizado número 16, para permitir a determinação do volume de água escoado superficialmente.

A diferença entre a lâmina de água aplicada e a lâmina de escoamento superficial, medida experimentalmente, corresponde à lâmina infiltrada. A lâmina de escoamento superficial foi obtida pela relação entre o volume de água escoado e a área útil da parcela experimental. $\mathrm{O}$ volume de água escoado foi medido em área cultivada sob os sistemas de plantio convencional (PC) e plantio direto (PD), conforme esquema de sucessão de cultivos apresentado na Tabela 1.

As culturas sucessoras à cultura do milho, das parcelas correspondentes ao sistema de plantio direto, foram manejadas com rolo-faca na primeira quinzena de agosto de 2002. No sistema convencional, foi feita a incorporação das culturas sucessoras à cultura do milho na primeira quinzena de setembro de 2002, utilizando-se de grade aradora, conforme uso tradicional na região. Após o manejo das culturas sucessoras, o infiltrômetro de aspersão foi instalado em cada parcela para as determinações de campo do volume escoado.

A estimativa de perda de solo e água foi feita em cinco tratamentos para o sistema de preparo convencional (PC) e cinco tratamentos para o plantio direto (PD), assim denominado: sucessão milhopousio em PC (CP); sucessão milho-trigo em PC (CT); sucessão milho-nabo em PC (CN); sucessão milho-ervilhaca em PC (CE); sucessão milho-aveia em PC (CA); sucessão milho-pousio em PD (DP); sucessão milho-trigo em PD (DT); sucessão milho-nabo em PD (DN); sucessão milho-ervilhaca em 
PD (DE); sucessão milho-aveia em PD (DA). Os tratamentos foram dispostos no delineamento experimental de blocos casualizados, com quatro repetições, totalizando 40 parcelas experimentais.

TABELA 1. Sistema de plantio e sucessão de culturas no período de 1999 a 2002.

\begin{tabular}{clll}
\hline \multirow{2}{*}{$\begin{array}{c}\text { Sistema de } \\
\text { Plantio }\end{array}$} & \multicolumn{3}{c}{ Sucessão de Cultura } \\
\cline { 2 - 4 } & \multicolumn{1}{c}{ Ano Agrícola } \\
\cline { 2 - 4 } Plantio & pousio & trigo & outubro-2000-2001 a agosto-2002 \\
\hline nabo forrageiro & ervilhaca-peluda & aveia \\
Convencional & ervilhaca-peluda & trigo \\
& ervilhaca-peluda & pousio & nabo forrageiro \\
& trigo & nabo forrageiro & pousio \\
\hline \multirow{2}{*}{ Plantio } & pousio & trigo & aveia \\
Direto & nabo forrageiro & pousio & ervilhaca-peluda \\
& aveia & ervilhaca-peluda & trigo \\
& ervilhaca-peluda & aveia & nabo forrageiro \\
& trigo & nabo forrageiro & pousio \\
\hline
\end{tabular}

$\mathrm{Na}$ área experimental, foram retiradas amostras de solo com três repetições por parcela, para a realização das análises químicas e físicas, conforme relacionadas a seguir, de acordo com EMBRAPA (1979):

- Análise textural: foram realizadas em amostras de solo coletadas na camada de 0-20 $\mathrm{cm}$ de profundidade.

- Análise de carbono orgânico total e matéria orgânica: foram coletadas amostras de solo com trado, na profundidade de $0-10 \mathrm{~cm}$ em cada parcela (repetição), a fim de melhor representar a variação espacial dos tratamentos.

- Densidade e porosidade do solo: foram coletadas amostras indeformadas de solo com os anéis volumétricos, de $25 \mathrm{~mm}$ de altura por $50 \mathrm{~mm}$ de diâmetro, centralizados nas profundidades de 7,5 $\mathrm{cm}$ e $22,5 \mathrm{~cm}$.

Em cada tratamento, foram ainda avaliadas as massas de matéria seca dos restos culturais, a declividade da parcela útil, umidade inicial do solo, tempo de início de escoamento superficial e energia cinética da precipitação.

- Massa da matéria seca: foram coletados, após os testes com o infiltrômetro, todos os restos culturais presentes na área útil $\left(0,70 \mathrm{~m}^{2}\right)$ de cada parcela experimental, colocados em sacos de papel e secos em estufa de ar forçado com temperatura em torno de $60^{\circ} \mathrm{C}$ e, posteriormente, determinada a massa da matéria seca.

- Umidade inicial do solo: antes do início dos testes com o infiltrômetro, foram coletadas três amostras de solo em duas profundidades $(0-15$ e 15-30 cm), com trado, para a determinação da umidade inicial do solo.

- Tempo de início do escoamento superficial: a fim de verificar o intervalo de tempo decorrido entre o início da aplicação da chuva e o início do escorrimento superficial, era cronometrado o tempo assim que se iniciava a aplicação da água na área útil da parcela.

- Energia cinética: foram anotadas, para possibilitar o cálculo da energia cinética por meio de programa computacional desenvolvido por ALVES SOBRINHO et al. (2001), a altura do bico, a pressão de serviço e a intensidade de precipitação no final de cada teste com o simulador. 


\section{Estimativa das perda de solo e de água}

Antes de iniciar a coleta dos dados de escoamento superficial, as parcelas receberam um prémolhamento, 24 horas antes dos testes, com o objetivo de oferecer condições de umidade mais uniformes a todas elas, constituindo-se um pré-requisito necessário antes da aplicação da chuva artificial (COGO et al., 1984). Para isso, o simulador foi regulado para aplicar uma intensidade de chuva, em torno de $60 \mathrm{~mm} \mathrm{~h}^{-1}$, durante tempo suficiente para saturar o solo, sem que houvesse escoamento superficial e, conseqüentemente, carreamento de solo para a calha coletora.

Após o pré-molhamento das parcelas, as avaliações de perdas de solo e água tiveram início com a coleta de sete amostras do volume escoado em cada parcela, em recipientes de um litro, em intervalos de 5 min entre cada amostra, conforme VARELLA (1999). A coleta da primeira amostra teve início quando foi verificado o escoamento inicial de água na calha coletora. Se, depois de decorridos os 5 min, o recipiente não estivesse completamente cheio, a coleta era interrompida, o volume registrado e era iniciada imediatamente a coleta da amostra seguinte. Ao contrário, se durante o intervalo de 5 min o recipiente ficasse completamente cheio, a coleta era interrompida e o tempo registrado. Neste caso, a amostragem seguinte era feita depois de decorridos os 5 minutos. O intervalo de tempo compreendido entre o início da aplicação da chuva e o início da coleta foi identificado no início da avaliação para cada parcela do experimento.

No final da avaliação de campo, as amostras eram encaminhadas para o laboratório e permaneciam em frascos vedados até ser feita a estimativa da massa de solo e do volume de água.

A estimativa da quantidade de solo e água, presentes em cada amostra, foi feita da seguinte maneira: mediu-se o volume de solução (solo e água) em proveta graduada, depois essas amostras foram colocadas em frascos (de um litro), pesadas e acrescentado ácido $\mathrm{HCl}(1 \mathrm{~N})$, para que houvesse a floculação do solo. Após a floculação, era retirado o excesso de água e colocadas em frascos de alumínio, devidamente pesados e colocados em estufa à temperatura de $60^{\circ} \mathrm{C}$, por período de tempo necessário, visando à completa evaporação da água contida nas mesmas. Em seguida, o solo seco foi pesado e calculado o volume de solo presente, com base na densidade de partícula $\left(2,75 \mathrm{~g} \mathrm{~cm}^{-3}\right) . \mathrm{O}$ volume de solo encontrado foi subtraído do volume total da solução, assim determinando a quantidade de água presente em cada amostra.

Para a análise estatística, foi utilizado o programa SAEG (Sistema de Análises Estatística e Genética) a fim de obter equações de regressão que melhor representassem a variação das perdas de solo e água, em função do tempo de aplicação da chuva.

\section{RESULTADOS E DISCUSSÃO}

\section{Alguns aspectos químicos e físicos da área experimental}

O sistema de preparo convencional apresentou tendência de valores maiores para a densidade do solo, na camada correspondente à profundidade de $22,5 \mathrm{~cm}$, ocorrendo o inverso no plantio direto, no qual foram observados valores maiores na camada em que o anel volumétrico foi centrado a 7,5 cm de profundidade (Tabela 2). Pode-se inferir, assim, que, no preparo convencional, a camada compactada encontra-se em profundidades maiores, isso devido ao revolvimento superficial do solo no preparo do mesmo. No plantio direto, a camada compactada encontra-se em menores profundidades devido, provavelmente, à passagem de máquinas e à pressão que estas exercem sobre o solo.

Podemos observar que, no preparo convencional, a porcentagem de macroporos, na primeira camada de solo, foi superior ao plantio direto, provavelmente devido ao revolvimento do solo pelo preparo do mesmo. Foi observado aumento da microporosidade na camada mais profunda, provavelmente devido ao carregamento de partículas de solo para as camadas mais profundas. 
TABELA 2. Densidade, macro e microporosidade e porosidade total do solo da área experimental.

\begin{tabular}{|c|c|c|c|c|c|c|c|c|}
\hline \multirow{3}{*}{ Trat. } & \multicolumn{2}{|c|}{$\begin{array}{l}\text { Densidade } \\
\left(\mathrm{g} \mathrm{cm}^{-3}\right)\end{array}$} & \multicolumn{2}{|c|}{$\begin{array}{c}\text { Macroporosidade } \\
(\%)\end{array}$} & \multicolumn{2}{|c|}{$\begin{array}{c}\text { Microporosidade } \\
(\%)\end{array}$} & \multicolumn{2}{|c|}{$\begin{array}{c}\text { Porosidade Total } \\
(\%)\end{array}$} \\
\hline & \multicolumn{8}{|c|}{ Profundidade $(\mathrm{cm})$} \\
\hline & 7,5 & 22,5 & 7,5 & 22,5 & 7,5 & 22,5 & 7,5 & 22,5 \\
\hline$\overline{\mathrm{CP}}$ & $1,32 \mathrm{~A}$ & $1,40 \mathrm{~A}$ & $7,97 \mathrm{~A}$ & $6,70 \mathrm{~B}$ & $48,66 \mathrm{~A}$ & $46,32 \mathrm{~A}$ & $56,63 \mathrm{~A}$ & $53,02 \mathrm{~B}$ \\
\hline CT & $1,23 \mathrm{~B}$ & $1,29 \mathrm{~B}$ & $6,28 \mathrm{~A}$ & $5,07 \mathrm{~B}$ & $49,26 \mathrm{~A}$ & $49,06 \mathrm{~A}$ & $55,54 \mathrm{~A}$ & $54,12 \mathrm{~B}$ \\
\hline $\mathrm{CN}$ & $1,25 \mathrm{~B}$ & $1,27 \mathrm{~B}$ & $4,18 \mathrm{~B}$ & $4,28 \mathrm{~B}$ & $49,06 \mathrm{~A}$ & $49,60 \mathrm{~A}$ & $53,24 \mathrm{~B}$ & $53,88 \mathrm{~B}$ \\
\hline $\mathrm{CE}$ & $1,25 \mathrm{~B}$ & $1,35 \mathrm{~A}$ & $5,92 \mathrm{~A}$ & $6,56 \mathrm{~B}$ & $48,30 \mathrm{~A}$ & $50,15 \mathrm{~A}$ & $54,22 \mathrm{~B}$ & $56,71 \mathrm{~A}$ \\
\hline $\mathrm{CA}$ & $1,31 \mathrm{~A}$ & $1,29 \mathrm{~B}$ & $4,45 \mathrm{~B}$ & $5,62 \mathrm{~B}$ & 47,94 A & $48,10 \mathrm{~A}$ & $52,39 \mathrm{~B}$ & $53,72 \mathrm{~B}$ \\
\hline Média & 1,27 & 1,32 & 5,76 & 5,65 & 48,64 & 48,65 & 54,40 & 54,29 \\
\hline$\overline{\mathrm{DP}}$ & $1,40 \mathrm{~A}$ & $1,34 \mathrm{~A}$ & $5,20 \mathrm{~A}$ & $6,86 \mathrm{~B}$ & $49,55 \mathrm{~A}$ & $51,32 \mathrm{~A}$ & $54,75 \mathrm{~A}$ & $58,19 \mathrm{~A}$ \\
\hline DT & $1,34 \mathrm{~A}$ & $1,30 \mathrm{~B}$ & $6,46 \mathrm{~B}$ & $9,18 \mathrm{~A}$ & $48,67 \mathrm{~A}$ & $49,15 \mathrm{~A}$ & $55,14 \mathrm{~A}$ & $58,33 \mathrm{~A}$ \\
\hline DN & $1,32 \mathrm{~A}$ & $1,23 \mathrm{~B}$ & $3,80 \mathrm{~B}$ & $5,84 \mathrm{~B}$ & $48,30 \mathrm{~A}$ & $48,41 \mathrm{~A}$ & $52,09 \mathrm{~B}$ & $54,25 \mathrm{~B}$ \\
\hline $\mathrm{DE}$ & $1,36 \mathrm{~A}$ & $1,26 \mathrm{~B}$ & $3,97 \mathrm{~B}$ & 5,99 B & $49,80 \mathrm{~A}$ & $50,68 \mathrm{~A}$ & $53,77 \mathrm{~B}$ & $56,67 \mathrm{~A}$ \\
\hline DA & $1,33 \mathrm{~A}$ & $1,28 \mathrm{~B}$ & $4,48 \mathrm{~B}$ & $4,42 \mathrm{~B}$ & $48,53 \mathrm{~A}$ & 49,41A & $53,00 \mathrm{~B}$ & $53,82 \mathrm{~B}$ \\
\hline Média & 1,35 & 1,28 & 4,78 & 6,46 & 48,97 & 49,79 & 53,75 & 56,25 \\
\hline
\end{tabular}

Valores médios seguidos da mesma letra, na coluna, não diferem entre si, pelo Teste de Agrupamento Scott-Knott.

Pelos resultados obtidos, verifica-se que os sistemas de manejo não influenciaram nos teores de carbono orgânico total e matéria orgânica, visto que os valores foram próximos nos dois sistemas de cultivo. A massa seca no sistema convencional foi inferior à presente no sistema de plantio direto em todas as sucessões de cultura, diferindo estatisticamente entre os sistemas (Tabela 3), uma vez que foi incorporada.

TABELA 3. Valores médios da massa de matéria seca (MS), matéria orgânica e carbono.

\begin{tabular}{lccc}
\hline Tratamentos & MS $(\mathrm{g})$ & Carbono $\left(\mathrm{g} \mathrm{kg}^{-1}\right)$ & $\mathrm{MO}\left(\mathrm{g} \mathrm{kg}^{-1}\right)$ \\
\hline CP & $82,15 \mathrm{~A}$ & $18,05 \mathrm{~A}$ & $31,15 \mathrm{~A}$ \\
$\mathrm{CT}$ & $73,05 \mathrm{~A}$ & $16,75 \mathrm{~A}$ & $28,80 \mathrm{~A}$ \\
$\mathrm{CN}$ & $55,38 \mathrm{~A}$ & $17,05 \mathrm{~A}$ & $29,43 \mathrm{~A}$ \\
CE & $61,23 \mathrm{~A}$ & $17,10 \mathrm{~A}$ & $29,48 \mathrm{~A}$ \\
$\mathrm{CA}$ & $212,35 \mathrm{~A}$ & $17,25 \mathrm{~A}$ & $29,25 \mathrm{~A}$ \\
\hline Média & 96,83 & 17,24 & 29,62 \\
\hline DP & $453,80 \mathrm{~B}$ & $17,15 \mathrm{~A}$ & $29,58 \mathrm{~A}$ \\
DT & $500,78 \mathrm{~B}$ & $16,58 \mathrm{~A}$ & $28,55 \mathrm{~A}$ \\
DN & $574,85 \mathrm{~B}$ & $17,30 \mathrm{~A}$ & $29,85 \mathrm{~A}$ \\
DE & $345,70 \mathrm{~B}$ & $17,98 \mathrm{~A}$ & $30,98 \mathrm{~A}$ \\
DA & $559,03 \mathrm{~B}$ & $18,50 \mathrm{~A}$ & $31,90 \mathrm{~A}$ \\
\hline Média & 486,83 & 17,50 & 30,17
\end{tabular}

Valores médios seguidos da mesma letra, na coluna, não diferem entre si, pelo Teste de Agrupamento Scott-Knott.

Não houve diferença estatística entre os sistemas de cultivo para o carbono orgânico total e matéria orgânica; isso pode ser devido ao manuseio das culturas sucessoras ter sido feito pouco tempo antes da realização dos testes, não havendo tempo para as restevas das mesmas se decomporem e também porque, na área experimental, vem sendo feito o plantio direto há cerca de três anos apenas. DALLA ROSA (1981); SILVA \& MIELNICZUK (1997), citados por BERTOL et al. (2001), comentam que sistemas de manejo do solo que promovem intenso revolvimento na camada superficial podem favorecer a decomposição da matéria orgânica, ocasionando efeito prejudicial na qualidade estrutural do solo e que a presença de camadas compactadas em subsuperfície, nesses sistemas de 
manejo, refletem uma degradação estrutural, com aumento da densidade e reduções do tamanho médio dos agregados, volume e tamanho dos macroporos, desenvolvimento radicular das plantas e taxa básica de infiltração de água. Por outro lado, afirmam que sistemas de manejo, caracterizados pelo não-revolvimento do solo e com a manutenção de resíduos vegetais na superfície, favorecem o aporte de carbono orgânico, o que é fundamental para a manutenção e/ou melhoria da estrutura do solo.

\section{Perdas de solo e de água}

A umidade inicial do solo foi semelhante para todos os tratamentos, contudo o tempo de início do escoamento superficial foi, em média, superior no sistema de preparo convencional devido à presença de pouca palha na superfície do solo (Tabela 4). De acordo com ALVES \& CABEDA (1999), no plantio direto, a presença de resíduos protege e evita alterações na superfície do solo, pois os mesmos dissipam a energia cinética das chuvas, enquanto a ação da grade, no preparo convencional, promove desagregação no perfil do solo reduzindo o escoamento superficial e, por conseguinte, favorecendo a infiltração inicial da água. Entretanto, após algum tempo, no preparo convencional, a desagregação superficial ocasionada pela ação do impacto da chuva com o conseqüente efeito do salpico reverte o processo.

Analisando ainda a Tabela 4, verifica-se que, no preparo convencional seguido de pousio, correspondente ao tratamento $\mathrm{CP}$, o tempo de início de escoamento foi superior aos tempos dos demais tratamentos avaliados e, por consequiência, a ação da chuva simulada foi também maior na superfície do solo, ação essa caracterizada pelo maior valor de energia cinética. Esse tempo maior pode ser explicado pelo fato de ter sido realizado o preparo do solo com grade, em todos os tratamentos, de forma a uniformizar procedimentos, cerca de cinco dias antes das avaliações de campo com o simulador de chuva. O preparo, ao proporcionar maior macroporosidade superficial, aumenta o tempo necessário para a saturação do solo. Nas parcelas em pousio, após a colheita do milho, foi observada a formação de torrões visivelmente maiores proporcionada pela ação da grade. Nesse tratamento, em virtude da falta de proteção da superfície do solo, o sulcamento foi mais acentuado que nos demais, favorecendo o aumento do tempo de início do escoamento.

Os valores médios de massa de solo e volume de água escoado ao final da aplicação da chuva simulada de intensidade de $60 \mathrm{~mm} \mathrm{~h}^{-1}$, em preparo convencional e em plantio direto, para as diferentes culturas de sucessão, são apresentados na Tabela 5.

TABELA 4. Valores médios de umidade inicial do solo (Ui), tempo do início do escoamento superficial (Ti), intensidade de precipitação (Ip) e energia cinética (Ec) nos testes realizados.

\begin{tabular}{lccccc}
\hline Tratamentos & $\begin{array}{c}\text { Ui 0-15 } \\
(\%)\end{array}$ & $\begin{array}{c}\text { Ui 15-30 } \\
(\%)\end{array}$ & $\begin{array}{c}\text { Ti } \\
(\text { minuto })\end{array}$ & $\begin{array}{c}\text { Ip } \\
\left(\mathrm{mm} \mathrm{h}^{-1}\right)\end{array}$ & $\begin{array}{c}\text { Ec } \\
\left(\mathrm{Jm}^{-2}\right)\end{array}$ \\
\hline $\mathrm{CP}$ & $11,41 \mathrm{~A}$ & $12,67 \mathrm{~A}$ & $38,83 \mathrm{~A}$ & $56,07 \mathrm{~B}$ & $1.678,10 \mathrm{~A}$ \\
$\mathrm{CT}$ & $12,32 \mathrm{~A}$ & $12,96 \mathrm{~A}$ & $20,15 \mathrm{~B}$ & $56,18 \mathrm{~B}$ & $1.255,98 \mathrm{C}$ \\
$\mathrm{CN}$ & $12,39 \mathrm{~A}$ & $13,15 \mathrm{~A}$ & $13,03 \mathrm{~B}$ & $60,89 \mathrm{~A}$ & $1.188,50 \mathrm{D}$ \\
$\mathrm{CE}$ & $12,46 \mathrm{~A}$ & $11,75 \mathrm{~A}$ & $19,45 \mathrm{~B}$ & $57,86 \mathrm{~B}$ & $1.277,12 \mathrm{C}$ \\
$\mathrm{CA}$ & $13,39 \mathrm{~A}$ & $14,02 \mathrm{~A}$ & $16,66 \mathrm{~B}$ & $57,68 \mathrm{~B}$ & $1.207,91 \mathrm{D}$ \\
\hline Média & 12,39 & 12,91 & 21,62 & 57,74 & $1.325,26$ \\
\hline $\mathrm{DP}$ & $12,76 \mathrm{~A}$ & $12,57 \mathrm{~A}$ & $11,50 \mathrm{~B}$ & $56,75 \mathrm{~B}$ & $1.069,73 \mathrm{E}$ \\
$\mathrm{DT}$ & $13,58 \mathrm{~A}$ & $13,00 \mathrm{~A}$ & $18,10 \mathrm{~B}$ & $63,61 \mathrm{~A}$ & $1.369,23 \mathrm{~B}$ \\
$\mathrm{DN}$ & $14,25 \mathrm{~A}$ & $13,92 \mathrm{~A}$ & $14,03 \mathrm{~B}$ & $58,57 \mathrm{~B}$ & $1.164,11 \mathrm{D}$ \\
DE & $13,49 \mathrm{~A}$ & $14,46 \mathrm{~A}$ & $13,76 \mathrm{~B}$ & $59,89 \mathrm{~A}$ & $1.183,79 \mathrm{D}$ \\
DA & $13,62 \mathrm{~A}$ & $13,66 \mathrm{~A}$ & $13,96 \mathrm{~B}$ & $57,75 \mathrm{~B}$ & $1.146,17 \mathrm{D}$ \\
\hline Média & 13,54 & 13,52 & 14,27 & 59,31 & $1.184,58$ \\
\hline
\end{tabular}

Valores médios seguidos da mesma letra, na coluna, não diferem entre si, pelo Teste de Agrupamento Scott-Knott. 
TABELA 5. Valores médios de perdas de solo $\left(\mathrm{g} \mathrm{m}^{-2}\right)$ e de água $\left(10^{-3} \mathrm{~m}^{3} \mathrm{~m}^{-2}\right)$ acumulados em plantio convencional e direto para as diferentes culturas de sucessão ao milho.

\begin{tabular}{|c|c|c|c|c|c|c|c|c|c|c|}
\hline \multirow{2}{*}{ Tempo } & \multicolumn{10}{|c|}{ Tratamentos } \\
\hline & $\mathrm{CP}$ & CT & $\mathrm{CN}$ & $\mathrm{CE}$ & CA & DP & DT & DN & $\mathrm{DE}$ & DA \\
\hline \multicolumn{11}{|c|}{ Perda de solo $\left(\mathrm{g} \mathrm{m}^{-2}\right)$} \\
\hline 5 & 0,49 & 3,75 & 4,45 & 1,48 & 0,93 & 0,40 & 0,12 & 0,32 & 0,62 & 0,87 \\
\hline 10 & 1,06 & 6,91 & 9,94 & 2,83 & 1,61 & 0,78 & 0,35 & 0,68 & 1,25 & 1,63 \\
\hline 15 & 2,14 & 10,99 & 14,91 & 4,51 & 2,26 & 1,08 & 0,49 & 0,98 & 1,70 & 2,15 \\
\hline 20 & 3,17 & 15,71 & 20,58 & 6,37 & 2,97 & 1,34 & 0,69 & 1,33 & 2,15 & 2,54 \\
\hline 25 & 4,30 & 20,77 & 26,35 & 8,32 & 3,70 & 1,55 & 0,82 & 1,58 & 3,28 & 3,01 \\
\hline 30 & 6,09 & 27,29 & 34,01 & 10,77 & 4,60 & 1,76 & 0,93 & 1,79 & 3,71 & 3,50 \\
\hline 35 & $7,50 \mathrm{~B}$ & $40,61 \mathrm{~A}$ & $47,75 \mathrm{~A}$ & $13,45 \mathrm{~B}$ & $5,34 \mathrm{~B}$ & $1,96 \mathrm{~B}$ & $1,09 \mathrm{~B}$ & $2,00 \mathrm{~B}$ & $4,19 \mathrm{~B}$ & 3,96 B \\
\hline \multicolumn{11}{|c|}{ Perda de água $\left(10^{-3} \mathrm{~m}^{3} \mathrm{~m}^{-2}\right)$} \\
\hline 5 & 0,33 & 0,68 & 0,70 & 0,57 & 0,37 & 0,89 & 0,17 & 0,30 & 0,27 & 0,25 \\
\hline 10 & 0,83 & 1,54 & 1,57 & 1,31 & 0,76 & 1,94 & 0,34 & 0,72 & 0,89 & 0,67 \\
\hline 15 & 1,45 & 2,65 & 2,74 & 2,20 & 1,21 & 3,00 & 0,50 & 1,24 & 1,66 & 1,17 \\
\hline 20 & 2,21 & 3,92 & 4,40 & 3,23 & 1,63 & 3,91 & 0,70 & 1,75 & 2,21 & 1,73 \\
\hline 25 & 3,12 & 5,32 & 6,03 & 4,35 & 2,16 & 4,83 & 0,88 & 2,30 & 3,15 & 2,22 \\
\hline 30 & 4,19 & 6,67 & 7,85 & 5,59 & 2,72 & 5,73 & 1,06 & 2,88 & 4,11 & 2,78 \\
\hline 35 & $5,45 \mathrm{~B}$ & $8,35 \mathrm{~A}$ & $9,88 \mathrm{~A}$ & $6,93 \mathrm{~A}$ & $3,29 \mathrm{~B}$ & $6,62 \mathrm{~A}$ & $1,23 \mathrm{~B}$ & $3,50 \mathrm{~B}$ & $5,07 \mathrm{~B}$ & $3,44 \mathrm{~B}$ \\
\hline
\end{tabular}

Valores médios seguidos da mesma letra, na linha, não diferem entre si, pelo Teste de Agrupamento Scott-Knott.

$\mathrm{C}$ - sistema de preparo convencional; D - plantio direto; P - pousio; T - trigo; N - nabo; E - ervilhaca; A - Aveia.

No sistema de plantio direto, as perdas de solo, em média, foram menores do que as observadas no preparo convencional, possivelmente devido à cobertura do solo oferecer-lhe proteção contra o impacto das gotas de chuva e, ainda, ao fato de o solo ser menos resistente ao escoamento devido ao preparo, o que está de acordo com PRUSKI et al. (1997). Esses autores comentam que, quanto mais protegida pela cobertura vegetal estiver a superfície do solo contra a ação da chuva, tanto menor será a propensão de ocorrência de erosão. Além de aumentar a quantidade de água interceptada, a vegetação amortece a energia do impacto das gotas de chuva, reduzindo a desagregação dos solos, a obstrução dos poros e o selamento superficial do solo. A presença de cobertura vegetal na superfície também promove a redução da velocidade do escoamento superficial devido ao aumento da rugosidade hidráulica do percurso ao longo do qual ocorre o escoamento.

Nessas observações, devem ser levados em consideração também os valores médios de energia cinética da chuva simulada no período, conforme resultados apresentados na Tabela 4. Devido ao maior tempo de precipitação, considerando o tempo para início de escoamento mais o tempo de tomada de dados, o valor de energia cinética nos tratamentos relativos ao sistema de preparo convencional foi, em média, superior ao do plantio direto, o que vem confirmar os resultados obtidos.

Considerando o sistema de plantio convencional, verificou-se que os tratamentos em pousio (CP) e com aveia (CA), na sucessão, foram mais eficientes no controle da erosão e de perda de água. Esses resultados podem ser explicados considerando que foi verificado certo adensamento superficial do solo mais acentuado, no tratamento $\mathrm{CP}$, o que poderia estar dificultando a desagregação superficial do solo e, no tratamento CA, devido às características do sistema radicular da aveia em favorecer a infiltração de água com conseqüente redução de perdas de solo e de água.

Dentro do sistema plantio direto, o tratamento com pousio na sucessão apresentou maiores perdas de água, provavelmente porque o solo se encontrava muito adensado superficialmente. Esse adensamento, associado à cobertura do solo pelos restos de cultura propiciava, assim, menor efeito do impacto das gotas de chuva, com conseqüente redução da desagregação superficial do solo. $O$ tratamento sob cobertura da cultura de trigo no inverno, muito embora não tenha apresentado diferenças significativas, controlou melhor a erosão e a perda de água do que os tratamentos com 
cobertura de nabo, ervilhaca e aveia. Esses resultados estão de acordo com os obtidos por DECHEN et al. (1981). Esses autores, trabalhando sobre um Latossolo Roxo em condições de chuvas natural em Campinas -SP, constataram que, em geral, as gramíneas foram mais eficazes do que as leguminosas na diminuição das perdas de solo, em todos os estágios de crescimento das culturas.

Com os dados da Tabela 5, foram ajustadas equações de regressão, tendo como variáveis dependentes a massa de solo e o volume de água escoado e, como variável independente, o tempo de duração da chuva simulada. Na Tabela 6, apresentam-se essas equações, sendo o modelo potencial aquele que melhor se ajustou aos dados, tanto para perdas de solo quanto de água. Para todas as equações, o coeficiente de determinação foi superior a $98 \%$.

TABELA 6. Equações de regressão ajustadas entre as perdas acumuladas de solo (Ps) e água (Pa) em função do tempo de aplicação da chuva simulada (t).

\begin{tabular}{|c|c|c|c|c|}
\hline \multirow{2}{*}{ Tratamentos } & \multicolumn{2}{|c|}{ Plantio Convencional } & \multicolumn{2}{|c|}{ Plantio Direto } \\
\hline & Ps & $\mathrm{Pa}$ & Ps & $\mathrm{Pa}$ \\
\hline Sucessão n & Ps $=0,0449 t^{1,4278}$ & $\mathrm{~Pa}=0,0313 \mathrm{t}^{1,4346}$ & $P s=0,1164 t^{0,8055}$ & $\mathrm{~Pa}=0,1783 \mathrm{t}^{1,0252}$ \\
\hline Suce & $P s=0,4882 t^{1,1858}$ & $\mathrm{~Pa}=0,0808 \mathrm{t}^{1,2977}$ & $P s=0,0250 t^{1,0825}$ & $\mathrm{~Pa}=0,0332 \mathrm{t}^{1,0162}$ \\
\hline Sucessão 1 & $\mathrm{Ps}=0,6595 \mathrm{t}^{1,1669}$ & $\mathrm{~Pa}=0,0706 \mathrm{t}^{1,3787}$ & $P s=0,0746 t^{0,9423}$ & $\mathrm{~Pa}=0,0391 \mathrm{t}^{1,2671}$ \\
\hline Sucessão 1 & $\mathrm{Ps}=0,2192 \mathrm{t}^{1,1371}$ & $\mathrm{~Pa}=0,0700 \mathrm{t}^{1,2841}$ & Ps $=0,1240 t^{0,9898}$ & $\mathrm{~Pa}=0,0272 \mathrm{t}^{1,4799}$ \\
\hline Sucessão milho-aveia & Ps $=0,2063 \mathrm{t}^{0,9026}$ & $\mathrm{~Pa}=0,0581 \mathrm{t}^{1,1257}$ & $P s=0,2679 t^{0,7586}$ & $\mathrm{~Pa}=0,0293 \mathrm{t}^{1,3472}$ \\
\hline
\end{tabular}

\section{CONCLUSÕES}

As perdas de solo e de água foram mais acentuadas no sistema de cultivo convencional, em todos os tratamentos estudados.

As coberturas de trigo e aveia foram mais eficazes do que as coberturas de nabo e ervilhaca no controle da erosão hídrica, não apresentando diferença entre os dois sistemas de cultivo.

\section{REFERÊNCIAS}

ALVES SOBRINHO, T. Desenvolvimento de um infiltrômetro de aspersão portátil. 1997. 85 f. Tese (Doutorado em Irrigação e Drenagem) - Universidade Federal de Viçosa, Viçosa - MG, 1997.

ALVES SOBRINHO, T.; CARVALHO, D.F.; AQUINO, R.M.; MONTEBELLER, C.A. Programa computacional para a definição de parâmetros hidráulicos utilizados na determinação da energia cinética da chuva simulada em infiltrômetros de aspersão. Engenharia Rural, Piracicaba, v.12, n.1, p.28-35, 2001.

ALVES, M.C.; CABEDA, M.S.V. Infiltração de água em um Podzólico Vermelho-Escuro sob dois métodos de preparo, usando chuva simulada com duas intensidades. Revista Brasileira de Ciência do Solo, Viçosa - MG, v.23, n.4, p.753-61, 1999.

BERTOL, I.; BEUTLER, J.F.; LEITE, D.; BATISTELA, O. Propriedades físicas de um cambissolo húmico afetadas pelo tipo de manejo do solo. Scientiae Agrícola, Piracicaba, v.58, n.3, p.555-60, 2001.

BERTONI, J; LOMBARDI NETO, F. Conservação do Solo. Piracicaba: Livroceres, 1985. 392 p.

CARVAlHO, D.F.; MONTEBELlER, C.A.; CRUZ, E.S.; CEDDIA, M.B.; LANA, A.M.Q. Perdas de solo e água em um Argissolo Vermelho-Amarelo, submetido a diferentes intensidades de chuva simulada. Revista Brasileira de Engenharia Agrícola e Ambiental, Campina Grande, v.6, n.3, p.385-9, 2002. 
COGO, N.P.; MOLDENHAUER, W.C.; FOSTER, G.R. Soil loss reductions from conservation tillage practices as expressed by a mulch factor. Soil Science Society of America Journal, Madison, v.48, n.2, p.368-73, 1984.

DEBARBA, L.; AMADO, T.J.C. Desenvolvimento de sistemas de produção de milho no sul do Brasil com características de sustentabilidade. Revista Brasileira de Ciência do Solo, Viçosa - MG, v.21, n.3, p.473-80, 1997.

DECHEN, S.L.F.; LOMBARDI NETO, F.; CASTRO, O.M. Gramíneas e leguminosas e seus restos culturais no controle da erosão em Latossolo Roxo. Campinas. Revista Brasileira de Ciência do Solo, Campinas, v.5, n.2, p.133-7, 1981.

DEDECEK, R.A.; RESK, D.V.S; FREITAS JÚNIOR, E. Perdas de solo, água e nutrientes por erosão em Latossolo Vermelho-Escuro dos cerrados em diferentes cultivos sob chuva natural. Revista Brasileira de Ciência do Solo, Campinas, v.10, n.3, p.265-72, 1986.

EL-SWAIFY, S.A.; DANGLER, E.W. Rainfall erosion in the tropics: a state of art. In: KREBS, D.M. (Ed.). Determinants of soil loss tolerance. Madison: American Society of Agronomy, 1982. p.1-25.

ELTZ, F.L.F.; MEHL, H.U.; REICHERT, J.M. Perdas de solo e água em entressulcos em um Argissolo Vermelho-Amarelo submetido a quatro padrões de chuva. Revista Brasileira de Ciência do Solo, Campinas, v.25, n.2, p.485-93, 2001.

EMBRAPA. Serviço Nacional de Levantamento e Conservação de Solos. Manual de métodos de análise de solo. Rio de Janeiro, 1979. Não paginado.

HERNANI, L.C.; SALTON, J.C.; FABRICIO, A.C.; DEDECEK, R.; ALVES JÚNIOR, M. Perdas por erosão e rendimentos de soja e de trigo em diferentes sistemas de preparo de um Latossolo Roxo de Dourados -MS. Revista Brasileira de Ciência do Solo, Viçosa - MG, v.21, n.4, p.667-76, 1997.

LOMBARDI NETO, F.; BERTONI, J. Erodibilidade de solos paulistas. Campinas: Instituto Agronômico de Campinas, 1975. 12 p. (Boletim Técnico, 27).

PRUSKI, F.F.; SILVA, D.D.; SANTOS, W.L.; RODRIGUES, L.N.; ANTUNES, V.L. Infiltração da água no solo. Viçosa - MG: Engenharia na Agricultura, 1997. 26 p. (Caderno Didático, 25)

VARELLA, C.A.A. Efeito dos sistemas de cultivo nas perdas de água e solo. 1999. 93 f. Dissertação (Mestrado em Fitotecnia) - Universidade Federal Rural do Rio de Janeiro, Seropédica, 1999. 